\title{
Disposal of human milk donated to a human milk bank before and after measures to reduce the amount of milk unsuitable for consumption
}

\author{
Ana L. Grazziotin, ${ }^{1}$ Maria C. B. Grazziotin, ${ }^{2}$ Luiz A. J. Letti ${ }^{3}$
}

\begin{abstract}
Objective: To evaluate the causes of disposal of donated human milk and the impact of the measures taken to reduce the amount of milk unsuitable for consumption.

Methods: A quasi-experimental, observational, comparative study was conducted with different populations of external donors in 2006 and 2008. In 2006, a simple form was used to record the criteria for disposal of the donated milk. We also interviewed the donors to find the reason of changes in the milk. In 2008, a checklist containing comprehensive guidance for milk collection and pre-storage was handed out to the donors. Next, we continued to survey the disposal criteria after the intervention using the same form administered in 2006. A case was defined as all bottles of milk of the same donor discarded per day. Data were analyzed by calculations based on comparison of proportions for 2006 and 2008.

Results: Twenty-four percent of the milk collected was discarded in 2006, while in 2008 only $10.5 \%$ of the milk was discarded. There was significant reduction in the disposal of milk for the items: cigarette odor; forgetting the milk outside the refrigerator, inside it or on its door; problems with the freezer; frequent opening of the refrigerator and freezer; expiration date; and unidentified cases. However, there was a significant increase in milk disposal for first milk collection without guidance; use of inappropriate bottle; milk transportation from work to home; and indirect guidance.
\end{abstract}

Conclusions: The use of the step-by-step checklist had a positive impact on the reduction of the volume of donated milk discarded and changed the frequency of the causes of disposal, eliminating some of these causes.

J Pediatr (Rio J). 2010;86(4):290-294: Human milk, selection, donor, analysis.

\section{Introduction}

A major concern of human milk banks (HMB) is to have sufficient milk supplies to meet the demand. A manner to achieve this goal is by decreasing the volume discarded after the analysis of raw milk in the early stages of processing, that is, during screening upon milk delivery, after thawing based on the appearance and odor, and finally according to the titration of milk acidity. During these stages, the disposal of the milk collected from external donors at home is related to environmental contaminants because of failures in the collection technique, pre-storage, cold

1. Mestranda, Biologia Celular e Molecular, Universidade Federal do Paraná (UFPR), Curitiba, PR, Brazil.

2. Consultora Internacional em Lactação, International Board of Lactation Consultant Examiners. Coordenadora, Banco de Leite Humano, Hospital de Clínicas, UFPR, Curitiba, PR, Brazil. Professora, Saúde da Mulher e da Criança, Banco de Leite Humano, Hospital de Clínicas, UFPR, Curitiba, PR, Brazil.

3. Professor assistente I, Curso de Engenharia de Bioprocessos e Biotecnologia, UFPR, Curitiba, PR, Brazil.

Study conducted at the Human Milk Bank, Hospital de Clínicas, Universidade Federal do Paraná (UFPR), Curitiba, PR, Brazil.

Financial support: Hospital de Clínicas, Universidade Federal do Paraná (UFPR), Curitiba, PR, Brazil.

No conflicts of interest declared concerning the publication of this article.

Suggested citation: Grazziotin AL, Grazziotin MC, Letti LA. Disposal of human milk donated to a human milk bank before and after measures to reduce the amount of milk unsuitable for consumption. J Pediatr (Rio J). 2010;86(4):290-294.

Manuscript received Dec 17 2009, accepted for publication Apr 302010.

doi:10.2223/JPED.2014 
chain maintenance, management of the collection bottle, causing changes in the properties of milk and making it unfit for consumption.

Human milk has no physical barrier that prevents the presence of microorganism ${ }^{1}$ and it behaves like a semi-plastic fluid that can undergo changes at the molecular level. ${ }^{2}$ It is not sterile (has saprophytic flora) and may be affected by primary contamination (blood source) and secondary contamination (skin and environment) with microorganisms that penetrate the breast ${ }^{1-3}$ and, although it has effective bacteriostatic and bactericidal factors to protect it from its flora, it is not always as effective against external contaminants.1,2,4 Quality control starts before removing the first drop from the breast, starting with the guidelines provided to the donor and the cold chain maintenance, and continuing throughout all stages of milk processing until it is offered to newborns and preterm infants. ${ }^{2,3,5,6}$ High quality of human milk is essential for these babies' survival and to protect them against infections in general. ${ }^{7}$

At the HMB, after receipt of raw expressed human milk (REHM), the first stage of processing is the registration and screening of the milk, followed by storage, thawing, rescreening (presence of impurities, color, off flavor and Dornic acidity), rebottling, pasteurization, cooling, microbiological analysis, and final freezing. ${ }^{1,4,8}$ At each stage, milk is assessed, and those bottles approved in the previous stage go on to the next stage.

Considering the relevance of the topic, the objective of the present study was to evaluate the causes of disposal of donated human milk and the impact of the measures taken to decrease the amount of milk unsuitable for consumption.

\section{Methods}

We conducted a retrospective observational study using a comparative quasi-experimental design at the HMB of Hospital de Clínicas (HC), Universidade Federal do Paraná (UFPR), Curitiba, state of Paraná, Brazil. We surveyed and analyzed data about the milk discarded from all the 1,926 donors visited in 2006 and from all the 1,798 donors in 2008 after taking measures for focused assessment and guidance.

In January 2006, the investigation on milk disposal was initiated. We defined as a "case" all bottles of milk discarded per day from the same donor. To manage the data collect in 2006, a questionnaire named "Identification and measures taken in cases of non-compliant human milk," which included the name of the donor, total volume of milk, and the number of discarded bottles, was used to record the non-compliance criteria of the milk received (acidity, off flavor, packaging, impurities, color) and to enable traceability. At each subsequent home visit, milk disposal was reported to donors and we interviewed them to identify the possible failure in the process that involves the whole collection procedure, from sanitation to prestorage (temporary condition in which the product is kept until being delivered to the BMB).

Based on the fact that in 2007 the causes of disposal were still present, we decided to use a new form beginning in January 2008. This checklist (Figure 1) included the step-by-step procedure regarding collection technique, careful measures related to the collection bottle, washing hands and breasts, right place, devices used, pre-storage, among other items. During weekly home visits, the form was handed out to each donor along with an educational booklet. We informed the donors about each case of discarded milk during the subsequent home visit in order to get the checklist reviewed with the purpose of diagnosing a possible failure in the procedure and to record such failure on the form "Identification and measures taken in cases of noncompliant human milk." Data were analyzed by calculations based on comparison of proportions for 2006 and 2008.

This study was approved by the Research Ethics Committee of HC-UFPR under the number 2115.010/201001 and by the Certificate of Presentation Ethical Evaluation (CAAE) under the number 0313.0.208.000-10.

\section{Results}

In 2006, 898 cases of disposal were detected among 741 donors. In 2008, 501 cases of disposal were detected among 392 donors. The cause of disposal was identified in $596(66.36 \%)$ and $415(82.83 \%)$ cases for 2006 and 2008 , respectively. In terms of total volume collected, of the $2,340 \mathrm{~L}$ in $2006,24 \%$ were discarded; in 2008 , of the $2,029 \mathrm{~L}$ collected, $10.5 \%$ were discarded.

The causes of disposal were grouped according to the process stage, since milk expression until its delivery to the HMB in situations related to the collection, pre-storage, transportation, indirect guidance, other reasons for disposal, and unidentified cases. The data are shown in Table 1.

Based on the comparative analysis of the proportions of 2006 and 2008, we found a significant reduction $(p<0.05)$ in the disposal of milk for the items cigarette odor, forgetting the milk outside the refrigerator, inside it or on its door, problems with the freezer, frequently open the refrigerator compartment and the freezer, donation after the expiration date, and unidentified cases. The items first milk collection without guidance; use of inappropriate bottle; milk transportation from work to home; and indirect guidance showed significant increases $(p<0.05)$ in milk disposal.

\section{Discussion}

In the literature, there are several studies reporting the disposal of raw donated milk at HMB based on visual analysis, off flavor, and acidity titration test; however, we 


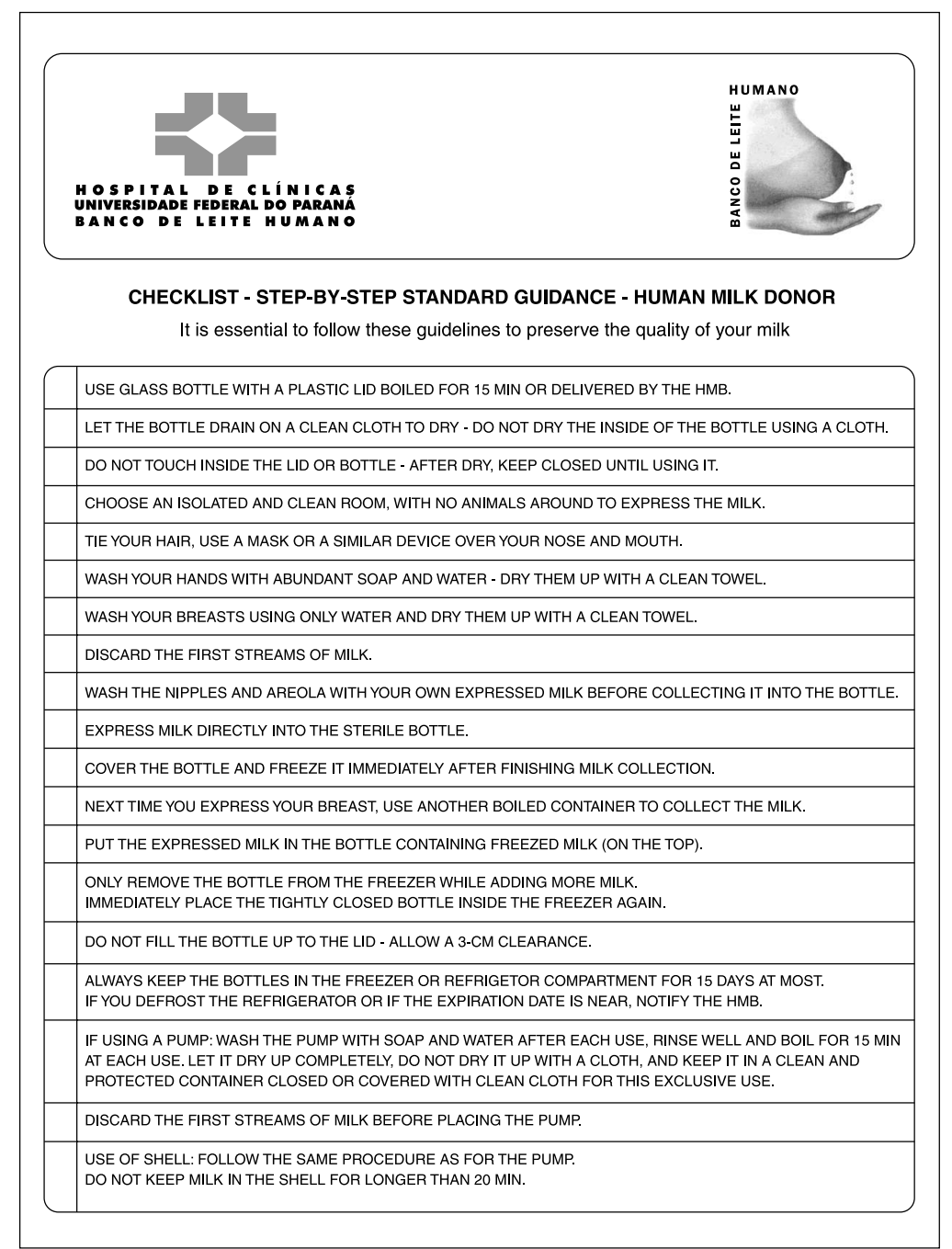

Figure 1 - Checklist of standard guidance for human milk donors

could not find reports investigating the causes leading to changes in the properties of milk that render it unfit for consumption.

Among the reasons for discarding milk grouped into the item collection, the reason first collection without guidance increased significantly in 2008. There was an increase in the number of advertising campaigns to attract donors, but the information provided was superficial and non-technical. Furthermore, there were cases in which the donors received guidance from other institutions or from laypeople, and when the home visit was requested to the HMB, the milk supply had already been delivered for donation.

Regarding to cigarette odor, lactose is able to absorb substances that vaporize to the environment and change the natural odor of human milk. ${ }^{2,9}$ These odor alterations are determined by off flavor, which is a safe method to find out if there are physical and chemical changes that make the milk unfit for consumption. ${ }^{10}$ In 2006, donors reported they were nonsmokers, but there were people smoking in the place where they expressed the milk. After receiving additional guidance about this aspect, there was a significant reduction in 2008, and none case was found for this item.

In the pre-storage group, the items forgetting the milk outside the refrigerator, inside it or on its door, problems with the freezer, frequently open the refrigerator and freezer, expired expiration date, and storage of milk in a neighbor's refrigerator showed reduction in the number of cases in 2008. The guidance using the checklist was considered the main reason for the improvements in these 
Table 1 - Impact of the causes found for the disposal of raw expressed human milk donated by external donors in 2006 and 2008 based on the calculation of comparison of proportions

\begin{tabular}{|c|c|c|c|c|}
\hline \multirow[b]{2}{*}{ Reason for milk disposal } & \multicolumn{2}{|c|}{ Cases (\%) } & \multirow[b]{2}{*}{$95 \% \mathrm{CI}$} & \multirow[b]{2}{*}{$\mathbf{p}$} \\
\hline & 2006 & 2008 & & \\
\hline \multicolumn{5}{|l|}{ During collection } \\
\hline Use of pump & 12.58 & 11.77 & -0.043 to 0.027 & 0.657 \\
\hline First collection without guidance & 3.89 & 13.57 & 0.064 to 0.129 & $0<10-6 *$ \\
\hline Use of shell & 4.12 & 2.99 & -0.031 to 0.008 & 0.265 \\
\hline General poor cleaning & 1.44 & 0.99 & -0.016 to 0.007 & 0.451 \\
\hline Failure to discard the first streams of milk & 1.33 & 0.79 & -0.016 to 0.005 & 0.330 \\
\hline Cigarette odor & 1.11 & 0 & -0.017 to -0.004 & $0.0015^{+}$ \\
\hline Use of non-sterile collection bottle & 1.11 & 1.39 & -0.009 to 0.015 & 0.653 \\
\hline Smoker donor & 0.22 & 0 & -0.005 to 0.001 & 0.157 \\
\hline \multicolumn{5}{|l|}{ During pre-storage } \\
\hline Forgetting the milk outside the refrigerator, inside it or on its door & 5.23 & 0 & -0.066 to -0.037 & $0<10-6^{+}$ \\
\hline Problems with the refrigerator (light, door or failure to freeze) & 2.78 & 4.79 & -0.001 to 0.041 & 0.068 \\
\hline Freezer containing meat, fish, seasonings, among other items & 2.67 & 1.79 & -0.024 to 0.006 & 0.274 \\
\hline Use of non-compliant bottle & 2.44 & 5.58 & 0.008 to 0.053 & $0.0063^{*}$ \\
\hline Problems with the freezer & 2.22 & 0.19 & -0.030 to -0.009 & $0.00014^{+}$ \\
\hline Frequently open the refrigerator compartment and the freezer & 1.89 & 0 & -0.027 to -0.010 & $0.000031^{\dagger}$ \\
\hline Non-sterile bottle to store milk & 1.44 & 1.59 & -0.011 to 0.014 & 0.828 \\
\hline Expired expiration date & 0.77 & 0 & -0.013 to -0.002 & $0.0079^{+}$ \\
\hline Freezing after several collections until filling up the bottle & 0.44 & 1.39 & -0.001 to 0.020 & 0.095 \\
\hline Storing the milk in the neighbor's refrigerator & 0.44 & 0 & -0.008 to -0.00009 & $0.045^{+}$ \\
\hline \multicolumn{5}{|l|}{ During transportation } \\
\hline \multicolumn{5}{|l|}{ Donor took the milk to the BMB using a } \\
\hline non-compliant transportation method & 1.33 & 1.99 & -0.007 to 0.020 & 0.368 \\
\hline Transportation of the milk from work to home for storage & 0.55 & 3.19 & 0.010 to 0.042 & $0.0014^{*}$ \\
\hline 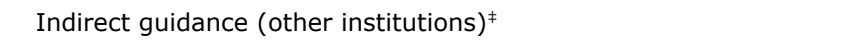 & 15.47 & 25.94 & 0.059 to 0.149 & $0.000005^{*}$ \\
\hline Other reasons for disposal§ & 2.78 & 4.79 & -0.001 to 0.041 & 0.068 \\
\hline Unidentified cases & 33.63 & 17.16 & -0.209 to -0.119 & $0<10-6^{+}$ \\
\hline Total cases & 100 & 100 & & \\
\hline
\end{tabular}

$95 \% \mathrm{Cl}=95 \%$ confidence interval.

* Situations that showed a significant increase of cases.

† Situations that showed a significant decrease of cases.

₹ Institutions just receive human milk from donors and then delivery it to the human milk bank.

$\S$ Kerosene odor, broken bottles, milk spill, presence of pets at the milk collection time, insufficient milk volume (less than $50 \mathrm{~mL}$ ).

situations. However, for the item use of non-compliant bottle, there was an increase in cases regardless of the guidance received, because in many situations there was increased volume of milk expressed during the week by the donor, exceeding the number of sterile bottles provided by the HMB for storage.

In terms of transportation, some donors worked in areas that were not covered by the route of home visits and, therefore, they took the expressed milk from work to their homes, located in regions where there was home visit. This was the only reason explaining disposal during transportation. REHM must be transported under cold chain conditions, inside isothermal packages made of smooth, durable, waterproof material that can be easily cleaned and used solely for that purpose, and for frozen milk transportation, the maximum temperature may not exceed $-1{ }^{\circ} \mathrm{C} \cdot 1,4,8,9$

As to indirect guidance, there was an increase in the number of cases of discarded milk. The HMB of HC-UFPR receives milk collected from lactating women who are trained in other hospitals where their children are hospitalized. These donors perform the collection at home and take the milk to the hospital, and then the milk is sent to the HMB of $\mathrm{HC}$ UFPR. Within such context, the staff of the HMB of HC-UFPR does not have direct contact with the donors. Even with the guidance lectures, there is high turnover of professionals in the hospitals, causing periods during which the professionals are not appropriately trained. This is probably the cause for the persistence of milk disposal related to the item indirect guidance during the years investigated. 
The unidentified cases represent the lack of diagnosis of the cause of disposal after a review by the HMB staff during a home visit. In 2006, the review was conducted through informal conversation between the professional and the donor. In 2008, there was a change in the strategy of review, which was combined with a step-by-step checklist. We believe that the use of the checklist is the reason for the significant decrease in the number of unidentified cases.

We also believe that the use of the checklist during the procedures of home visit led to a behavioral change in the donors, possibly because the checklist introduction allowed a closest relationship between professionals and donors. In 2006, only informal talks with the donors whose milk was discarded were performed. Donor embarrassment due to the received information and also professional embarrassment due to information given was observed in some cases. However, with the introduction of the checklist in 2008 , and the step-by-step explanation provided by the professional, there was improvement in the dialogue between professionals and donors, as well as in the interest shown by the donors on the use of their milk. We noticed that the checklist was adopted as a document of commitment by the donors, ensuring the quality of their milk.

Maternal milk is the first choice in terms of quality for all infants, and the milk of the HMB is the second best option, because even after processing the milk keeps the nutritional, metabolic, protective, and anti-infectious properties, ${ }^{2,7,11}$ especially for preterm infants who need to adapt their metabolism to the extrauterine environment to which they were exposed earlier than expected. To achieve a development as close as possible to the uterine environment, it is necessary to ensure the overall quality of the milk of the HMB. This should be the major concern of professionals and donors. Although pasteurization is a process that ensures the elimination of $99 \%$ of the saprophytic flora and $100 \%$ of the pathogenic flora, $1,2,4,8,9$ it is absolutely necessary to protect the milk from prior contamination in order to preserve its components until being offered to the hospitalized newborns. The fact that the HMB receives high quality milk is directly related to the care taken during collection and the awareness about the importance of providing human milk to newborns by the donors.

There are several studies on the quality of human milk in the literature; however, all of them aimed to find the causes of milk disposal in the internal control of the HMB, only through routine methods adopted in the REHM milk screening such as visual criteria, off flavor and acidity. Considering the lack of studies about the causes of milk disposal related to donors, the present study showed the real importance of achieving human milk traceability since the beginning of the collection process, in order to understand and struggle against the reasons that cause milk alterations, as well as to optimize the use of the milk received.

\section{References}

1. BRASIL. Ministério da Saúde. Normas e Manuais Técnicos, N117. Recomendações técnicas para o funcionamento de Bancos de Leite Humano. 4a Ed. Brasília: Ministério da Saúde. Reimpressão junho de 2001.

2. Almeida JA. Amamentação: um híbrido natureza-cultura. Rio de Janeiro: FIOCRUZ; 1999.

3. Mattar MJ, Kuzuhara JS, Gomes AM. Banco de Leite Humano. In: Neto CM, editor. FEBRASGO - Manual de orientação de aleitamento materno. São Paulo: Ponto; 2006. p.130-8.

4. BRASIL. Ministério da Saúde. Programa Nacional de Qualidade em Bancos de Leite Humano: curso de implantação. Brasília; 2003.

5. Almeida JA. Qualidade do leite humano coletado e processado em bancos de leite [dissertação]. Viçosa (MG): Universidade Federal de Viçosa; 1986.

6. Cavalcante JL, Telles FJ. Aspectos físicos-químicos do leite humano ordenhado cru e congelado. In: Buss PM, Almeida JA, Novak FR, editores. Teses. III Congresso Brasileiro de Bancos de Leite Humano. Rio de Janeiro: FIOCRUZ; 2002. p. 43.

7. Victora CG. Infection and disease: the impact of early weaning. Food Nutr Bull. 1996;17:390-6.

8. BRASIL. Agência Nacional de Vigilância Sanitária. Resolução RDC $\mathrm{n}^{0} 171$, de 4 de setembro de 2006. Dispõe sobre o regulamento técnico para funcionamento de BLH. Diário Oficial da União. Brasília, DF. 5/09/2006.

9. Brasil. Agência Nacional de Vigilância Sanitária. Banco de leite humano: funcionamento, prevenção e controle de riscos/Agência Nacional de Vigilância Sanitária. Brasília: Anvisa; 2008. 160p.

10. Novak FR, Junqueira AR, Dias Mde S, Almeida JA. Sensorial analysis of expressed human milk and its microbial load. J Pediatr (Rio J). 2008;84:181-4.

11. Vinagre RD, Diniz EM. O leite humano e sua importância na nutrição do recém-nascido prematuro. São Paulo: Atheneu; 2002.

Correspondence:

Maria Celestina Bonzanini Grazziotin

Banco de Leite Humano, Hospital de Clínicas

Universidade Federal do Paraná

Rua General Carneiro, 181 - Centro

CEP 80060-900 - Curitiba, PR - Brazil

Tel.: +55 (41) 3360.1867

E-mail: celestinabg@gmail.com 